\title{
AUMENTO ESTÉTICO DE COROA CLÍNICA: DESCRIÇÃO DE CASOS CLÍNICOS
}

Bruna Maggioni TEIXEIRA, Paula Mayumi NISHITA, Ana Paula BONOTTO, Laise BASSO, Cléverson SILVA

Vários estudos discutem a manipulação da exposição gengival para promover um sorriso esteticamente prazeroso. Recentemente, mais atenção tem sido dada ao problema da exposição excessiva da gengiva e ao potencial das cirurgias plásticas periodontais em melhorar a linha do sorriso. Neste trabalho apresentaremos dois casos clínicos que abordam técnicas distintas para o tratamento. Se o excesso de gengiva exposta estiver relacionado com tamanho insuficiente de coroa clínica, o melhor procedimento indicado é uma gengivectomia/gengivoplastia que pode ser ou não associada a uma osteotomia. Para a realização desse aumento, devem ser considerados fatores como localização da margem gengival em relação à junção cemento-esmalte, a crista óssea e a relação coroa-raiz-osso alveolar. No primeiro caso, a paciente G.A.S., 20 anos, gênero feminino, leucoderma, estudante de odontologia e que queixava-se de apresentar dentes curtos, após exame clínico e radiográfico, foi submetida a um procedimento único de gengivectomia como forma de tratamento para a sua queixa. No segundo caso, a paciente F.L.P., 21 anos, gênero feminino, estudante, que também queixava-se de apresentar dentes anteriores curtos, precisou ser submetida a um procedimento de gengivectomia associada a uma osteotomia. Nenhuma das duas pacientes apresentou recidiva após o tratamento.

Palavras chave: Gengivectomia; Gengivoplastia; Sorriso. 